commenced, I was requested to see a young lady, of vigorous constitution, many of whose sy mptoms were remarkably similar, although more severe. After haviug complained of catarrhal symptoms with frontal headache for some days, she began to expectorate blond. This expectoration continued at intervals thronghout four days, and, as far as could be judged from the handkerchiefs she used, to the extent of about a drachm of blood at a time. No pueumonic sputa were observed.

Pain, in this case, was both constant and severe. Its focus was ahout two inches to the right of the mid sternum, and it passed through to the back. There was not much cough, but frontal headache and debility were very marked. Occasionally the patient was delirious at night. In the situation from which the pain emanated I detected a very slight friction-sound, which lasted but a short time. 'I here was no other physical sign of moment.

The treatment consisted of tartarized antimony with mor. phia ; strong beef-tea and wine when needed. Sinapisms were found ineffective against the pain; but it was greatly relieved by the application of bran poultices as hot as conld be borne. Her illness continued about a fortuight, and convalescence was not protracted.

CAsE 3. - A bout the middle of January I saw in consultation with Mr. Lemon, of the Caledonian road, a patient whose symptoms were in several respects similar to those of the two foregoing. She was a lelicate, anæmic looking girl, and had been suffering for a few days from cough, with catarthal sputa, frontal headache, aud general debility. Her mother informed us that on the day previous to our visit the patient had coughed up a little pure blood. She complained also of pain under middle of sternum, passing to the back. We could discover no physical signs, except slight jerkiness of respiration, yet there was no reason for suspecting phthisis. We decided on giving quinine with morpbia, beef-tea, and, if necessary, wine; hot bran poultices for pain.

1 subsequen-ly heard from Mr. Lemon that the patient soon recovered, and that hæmoptysis did not recur.

CASE 4.-In this case I had the valuable assistance of Dr. Hess, of Artillery-place. In the beginning of February, a gentleman of middle age, and good al hough not robust constitution, was somewhat suddenly seized with cough, mucous expectoration, oppression at the chest, and frontal headache. After a few days be began to expectorate blood, and felt pain at a point about two inches below the right nipple, and a little towards the same side. This pain was severe and persistent, but the hæmoptysis continued longest, and more than a week elapsed before it entirely ceased. The sputa were at first viscid, but gradually bocame thinner and frothy. Blood never came up unmixed, but was frequently sufficient in quantity to com pletely colour the other expectorated matters. Hæmoptysis would be repeated often in the day, and always occurred on awaking in the morning. With the exception of a doubtful friction-sound, slight deficiency of respiration at the affected part, and a few sonorous râles, we could detect no physicit signs. The treatment consisted of salines, counter-irrita:ion, hot bran poultices, beef-tea, \&c.

This gentleman's illness lasted about a fortnight. By the aid of tonics and change of air he convalesced satisfactorily.

The question may be asked, were these cases of true influenza? or were they cases of inflimmatory catarrh? Although the symptoms of catarrh are common to influenza, it seemed plain to me from the first that the patients were suffering from in fluenza. The frontal headache, with an amount of debility dis proportionate to the other symptouns. and the great digestive disturbance, indicated the epidemic affection. 1 am borne out, too, by the fact that influenz $\mathfrak{l}$ is admitted to have lately pre vailed both in Paris and London. It was reasonable to conclude that a symptom not known to occur in inflammatory catarrh belonged to an epidemic remarkable for the versatility of its phenomena.

In the "Annals of Influenza," compiled by the late Dr. Thomp. son, I find this statement by Dr. Nelson Scott, in deseribing the "Influenza as it appeared in the Isle of Man in Spring, 1803:" "Some were afflicted with repeated attacks of epistaxis; and one patient had hæmoptoe to a serions degree, after the epidemic had left him, who had never before been subject to such an ailment. The patient with hæmoptoe had no here ditary claim to phthisis." Again, in Dr. Steeten's Report on the Euidemic of $1-36-37$, it is stated that " Mr. Smith, of Stroud, mentions that, in two cases occurring in his practice, it (the influenza) produced hremoptysis to an alarming extent.' Dr. Steeten also speaks of the sputa as "occasionally tinged with blood."
These are all the references to the occurrence of hæmoutysis in this disease $I$ have been able to find. It would be very interesting to ascertain whether it has been noticed by many practitioners lately. I have already discovered by inquiries that it has been by some. Thus Dr. Hess informs me that he had a case very similar to Case 4 above. I shall feel much obliged for any communications on the subject.

Amongst the out-patients at the Royal lnfirmary for Diseases of the Chest, I have recently observed some cases of pro. fuse epistaxis to have occurred in conjunction with catarrhal symptoms.

Old Burlington-strcet, April, 1862.

\section{ON A CASE OF DISLOCATION OF THE} HEAD OF THE THIGH-BONE INTO THE OBTURATOR FORAMEN, REDUCED WITH THE HEEL IN THE PERINEUM ;

AND REMARKS ON THE LIGAMENTUM TERES.

By JOHN ADAMS Esq., F.R.C.S., SURGEON TO THE LONDON HOSPITAL.

Mr attention was directed on the 28 th of April to a case which had been just admitted under the following circum. stances:-

A middle-aged man was assisting in the unloading of a cart filled with bales of wool, and was standing below to keep the foot passengers out of danger, when a large bale came to the ground from the cart and, falling on his head and neck, forced him to the earth. His body was bent forward at the time of the accident, and his legs were slightly separated. He was found to have sustained some injury to his right hip, and was brought immediately to the hospital.

He was in great agony, much depressed, and complained of pain in the pubic and perineal regions. A very cursory examination sufficed to prove the nature of the accident. The right thigh was separated from the left and somewhat advanced, and as the man lay upon the sofa the attempt to depress the thigh caused great pain. The foot was but slightly everted. On placing the hand beneath the pubis I found the adductors stretched forcibly over a firm unyielding mass-the head of the femur; the nates were completely depressed, the great trochanter having disappeared from view. I did not measure the length of the limb, for I was satisfied at once of the nature of the injury.

The reduction was accomplished under chloroform with the greatest facility in the following manner:- The patient lying fiat on his back on a sofa, I directed one of the housepupils to place himself as if about to reduce a dislocated shoulder of the right side, and to fix his heel in the perineum, defended by a square soft pad; inclining the fulcrum thus formed against the head of the thigh bone, a jack.towel was fixed by a clove-hitch knot above the knee, and by the aid of pullies the bone was retuced, and the head of the femur slipped at once into the acetabulum. The knees were tied together, and the man was sent to bed.

The simplicity of the proceeding was apparent, and I am sure that even without the aid of pullies a recent dislocation of this nature may be reduced as readily as a dislocated shoulder. There is no necessity to place the patient under the profound influence of chloroform ; it is enough in most cases to influence him so far that his attention is altogether diverted from the injury. I have never witnessed the attempt to reduce a dislocation of the hip-joint of this nature in this manner before but I dare say it has been done. I once saw my late colleague, Mr. Nathaniel Ward, reduce a dislocation of the thigh on to the dorsum ilii, with the heel in the perineum, in a child, and $I$ was much surprised at the readiness with which the affair was accomplished. The dislocation of the thigh-bone into the obturator foramen more closely reseml 1 is the dislocation of the humerus into the axilla than any othe $x$ form of dislncation; and there may be said to be a close analogy between them. A similar method of reducing the former, as is used in the latter, may therefore with propriety be employed, and the result of this case is a proof of its ready and successful application.

The condition of the ligamentum teres in cases of dislocation 1 of the hip can rare!y be ascertained; but $I$ am of opinion that 
this ligament is invariably torn. It is quite true that, after the capsular and accessory liraments are divided after death. the head of the thigh-bone can be displacel in to the obturator fora. men without rapture of the sound ligament; but this state of things is by no means represented during life, when all the muscles around the joint are in their norinal state of activity. I think, when dislocation into the obturator foramen occurs, that the ligament unquestionably gives way.

The use of the livamentum teres and its condition of ten. sion and relaxation duriug the varied movements of the thigh bone, are prohlems which liave only recently been solved. For many years I hal taught in my lectures that this ligament was employed in nicely and accurately baliancing the pelvis on the head of the thigh-bone, so as to obviate the tffects of shocks in the simple movements of the body in the erect posture; and I have been in the habit of strengthening my arrument by reference to the ligament as it is found in the shoulder joint of the frog, and to its absence in the elephant, in whlch animal it could be of no avail, as the pelvis stands vertically over the perpendicu'ar column of bones as they are arranged in the hind limb of this enormous animal. But I am satisfied that I did not quite truly interpret the use of this lizament, nor did I quite nnderstand it until my attention was drawn to it by the observations of Dr. Humphry, of Cunbridge, as given in his admirable work "On the Human Sk+leton." He has shown that this ligament is streteht $d$ or rendered tense when the thigh is bent upon the pelvis and addncted: and that its use, therefore, is to prevent the too powerful flexion of the limb. Nevertheless, 1 cannot but believe that this lirsament is useful in preventing the propagation of shooks to the peivis in the violent movements of the lower limbs, as in jumping from a height and in alighting upon the feet; for, under these circumstances, the hip joint is invariably flexed, and the liyament is consequenty rentered tense. The mode in which this dislocation occurs also strengthens this idea to a certuin extent, for it always happens when tbe hip joint is in a state of flexion, as in the case just mentioned, for the bale of goods came forcibly upon him whilst be was in a stooping position; aud it is very pro bable that the yielling of the thigh inwards or ontwards ma result from the mode in which the force is applied, and this probably determines the natare of the dislocation. I therefore regard the rupture of the ligamentum teres as the first neces. sary anatomical lesion, when dislocation happens into the obtu rator foramen.

St. Helen'seplaee, April, 1862

\section{ON THE PHYSTOLOGICAL ACTION OF THE TURKISH BATH.}

\section{By CHARLES HUNTER, ESQ, M.R.C.S. ENG.,} FORMEHLY HOUSR-SURGHON TO इ". GEORGE'S HOSPITAX.

\section{Its Order of Physiological Effects on the Skire and Lungs;} Conclusions.

Now that Turkish baths are rising up in all directions, and pamphlets are for ever praising up their merits to the skies, all couleur de rose, and diseases of all kinds are by their means premised both prevention and cure, it may be as well to place on record a word or two as to their physiological action on tho healthy individual. T.is appcars the more necessary, as the majority of otservations hitherto pubished have in general been very brief as regards the modus oprandi of the bath on the system, chiefly describing its great comfort, action on the skin, and the diseases it will cure.

Withoat denying the sensation of comfort axd luxury that some experience, or that some people take and repeat these baths with impunity, I would enforce, as observed by Sir Charles Scudamore with regard to the cold water cure, that that which is powerful for good must also be so for evil; and the same applies to the hot-air cure, which is an agent not to be trifted with, or usel in a reckless way, lest the cure turn out "a dead cure," as remarked in an excellent "Annotation" in THo LANCET of the 8th of March.

When the duration of time that is spent in "going through a Turkish bath" and its great temperature are considerel, $i$ is only reaconable to expect that some of the many who now flock indiscriminately to these baths should not be proof against the great heat, and should consequently find their vital powers taxed and their system weakened. How that weakening of the system is brought about will be seen by examining the sub. ject physiologically.

It may be premised that on an average two hours are occupied by the bathing processes, during the greater part of which time the bather is in a temperature varying from three to five times that of the external and accustomed atmosphere.

In this heat, or rather hot air containing a little vapour, the various functions of the body become affected in the following order :-

$$
\begin{aligned}
& \text { Primarily . }\{\text { The skin, and } \\
& \text { Secondly ... The circulation. } \\
& \text { Thirdly ... The cerebro-spinal, }
\end{aligned}
$$

1. The organs affected primarily are those into contact with which the hot air is elireelly brought.

2. The circulation is directly affected through the lungs and skin.

3. The other parts of the body mainly through the altered state of circulation.

1. The effect upon the stin. - On entering the first room, or tepilarinm. which may vary ${ }^{\mathrm{r} o m} 116^{\circ}$ to $130^{\circ} \mathrm{Fahr}$, the heated air is brought into contact with the skin of the whole body. The effect induced is one of direct stimulation. A glow is at first experienced, rather agreeable than otherwise, sometimes accompanied by a seuse of irritation, until diaphoresis commences. These cutaneous sensations are due to the combined effect of the heat without, and the afflux of blood to the vessels within.

But soon the skin perspires more or less freely, according to the heat of the bath, the diathesis of the patient, and the amount of water drunk. Into these details, however. I need not go, but simply state that an excessive drain is in some cases establisher from the skin through this heat-irritation; that many people lose regularly from two to four pounds weight in the bath, notwithstanding the amount of water drunk; that eight pounds lave been lust in one case that I know of, and, perhaps, more has been in other eases.

We need not wonder, then, th. first stimulates and then relaxes the skin-with the manipulation of the assistant with and withont soap and water, "that the rosy tint of the capillary plexus should glow through the transuarent covering," and thit one should be able "rearlily to detect a "comvanion of the bath' by his rosy aspect." (Wells.)

In moderation there can be no doubt that, the bath does good to the skin, by increasing in it the circulation, and at the same time eleansing it by getting rid of superfluous epithelium, glandular secretion, and watery exhalations; and as these become removed, cuticular respiration will become more free. But is it moderation to keep up a continuous drain from the skin for more than an hour at a time, and to repeat that process frequently? Is it not more rational to consider, with THE LA VCET, "that profuse perspiration, which these genrlemen regard with such triumph, is the protest of Nature ayainst their lot chambers?" Is not this draining away by the skin one of the causes of the weakness induced by the bath?

2. Upon the lungs. - When it is considered that the hot air of the "l urkish bath is brought as much into contact with every part of the lungs as it is with the surface of the skin, it need not be a stibject of wonder if the lungs become affected in their action.

On entering either the tcpidarium or the calidarium, a momontary oppressim of the breathing is sometimes felt. This oppression or stifliug sensation is greater according to the heat, aud will pass ofi sooner in the tepirlarium than in the hotter room. It devends upun a momentary concrestion of the lungs, dne vartly to the unacenstomed simulus of the heated air which air being specifically lighter, would contain less oxygen in each inspired portion.

In air at $116^{\circ}$ to $120^{\circ}$ Fahr. one may stay a long time without inconvenience to the breathing, save that every now and then a deep involuntary inspiration will take place; but in air heated to $150^{\circ}$ or $160^{\circ} \mathrm{Fahr}$. the oppression at the chest felt on entering will with many people continue; the breathing will xot be easy ; there will be "that want of refreshing sensation which acconpanies a full inspiration of cold air" that was felt by Solamler. Banks, and others, in their experiments-a want of that comfort, or rarher absence of sensation about the breath ing, which one enjoys at ordinary temperatures. And if these serisations. the ar mine, are not attender to, a sense of anxiet will be superadded, as in the case of Blagdeu, together with 